\title{
Identifying Clusters of Complex Urban-Rural Issues as Part of Policy Making Process Using a Network Analysis Approach: A Case Study in Bahía de Los Ángeles, Mexico
}

\author{
Javier Sandoval ${ }^{1, *}$, Manuel Castañón-Puga ${ }^{1, *}$, Carelia Gaxiola-Pacheco ${ }^{1}$ and \\ Eugenio Dante Suarez ${ }^{2}$ \\ 1 Computer Engineering Department, Autonomous University of Baja California, 22390 Tijuana, B.C., Mexico; \\ cgaxiola@uabc.edu.mx \\ 2 Finance \& Decision Sciences Department, Trinity University, San Antonio, TX 78212, USA; \\ esuarez@trinity.edu \\ * Correspondence: javier.sandoval10@uabc.edu.mx; (J.S.); puga@uabc.edu.mx (M.C.-P.)
}

Received: 1 January 2017; Accepted: 13 June 2017; Published: 19 June 2017

\begin{abstract}
Improving human settlements diagnosis is a key factor in effective urban planning and the design of efficient policy making. In this paper, we illustrate how network theory concepts can be applied to reveal the topological structure of functional relationships in a network of heterogeneous urban-rural issues. This mapping is done using clustering algorithms and centrality value techniques. By analyzing emergent groups of urban-rural related issues, our methodology was applied to a rural community, considering in this exercise environmental matters and real estate interests as a way to better understand the structure of salient issues in the context of its urban development program design. Results show clusters that arrange themselves not by an obvious similarity in their constituent components, but by relations observed in urban-rural settings that hint on the issues that the urban development program must focus. Due to its complex nature, the classification of these emerging clusters and how they must be treated in traditional planning instruments is a new challenge that this novel methodology reveals.
\end{abstract}

Keywords: clustering; urban issues; complexity; public policy; network theory

\section{Introduction}

Rural issues in Mexico have always been at the center of urban growth, mainly due to the communal nature of land property. This interrelationship has been so important over the years that the federal government recently created a Federal Department that in its name acknowledges the strong relations between urban-rural issues: The Department of Agrarian, Land and Urban Development (SEDATU in Spanish). This was a necessary action from an institutional standpoint; from a technical perspective, efforts are not complete: the literature that the federal government provides for making urban development programs is still outdated. Planning offices around the country still mostly rely on its suggested structure to analyze human settlements before designing urban planning policies, but these guides currently represent a generic diagnosis structure that essentially describes the status of the urban settlements under study. The official booklet known as the Municipal Urban Development Plan or Program: a Methodological Guide [1], establishes four broad and generic themes by which urban settlements must be characterized as the base for planning policies: Natural Physical Environment, Transformed Physical Environment, Socioeconomic Aspects, and Urban Development Administration and Management. Furthermore, this guide states that a hypothesis of structure and function of the urban system must be included, but it does not clarify how can this process is to be conducted. 
Recent advancements in the field of complexity can shed new light about innovative methods for studying human settlements, as the understanding of their functional relationships is one of the key factors for effective policy making regarding urban development [2]. The application of complexity to an urban context has been coined by Juval Portugali as Complexity Theories of Cities [3], which explores a variety of urban phenomena that were considered independent and previously studied under different methodologies [4], but are now considered interconnected in the intricacies of urban complexity [5]. The Complexity focus surpasses traditional urban policy making as it takes into account that policies have effects on other domains and that these domains interact with each other [6], thus identifying new relations and interactions in urban systems that allow more sustainable and successful solutions. In the context of policy making, it strives to identify cause-and-effect chains and extract knowledge from cities by revealing underlying mechanisms that lead to the observed behavior [7]. Because complex systems are networks made of nodes that interact with each other [8] and urban systems can be conceived as made of components with relations and interactions, a common way to study them has usually involved network theory [6]. Natural resource management [9], detection of socio-economic urban patterns [2], urban landscapes [10], traffic and transport [11,12], connectivity [13], markets, population [14], epidemics [15], land use change [16] and social networks [17] are some of the urban issues studied with this approach, becoming crucial to the understanding of features and dynamics of urban systems.

We illustrate in this work how concepts of network theory can be mapped to a list of heterogeneous and non-spatial complex urban issues of a rural locality, revealing an inherent network structure that can help us understand the underlying working principles and relations trough the emergence of clusters. We develop this methodology through an unsupervised learning exercise [18] of community detection with clustering algorithms and centrality metrics. This approach would help transcend the mere descriptive nature of traditional urban planning instruments and get closer to a more strategic approach of spatial planning, showing a settlement system in a structure understandable both to researchers and policymakers. This methodology was applied on the coastal rural locality of Bahía de Los Ángeles, Mexico, which is under intense environmental scrutiny and also affected by significant real estate interests.

Bahía de Los Ángeles is a coastal community with a rural character facing the Gulf of California located on the east side of the Baja California peninsula (Figure 1). It is part of the municipality of Ensenada, Mexico, with its first historical account of its existence going back as far as the 18th century. It only has about 800 inhabitants according to latest census data. The calm waters of the Gulf and the nearby archipelago of 16 islands give Bahía de Los Ángeles an outstanding natural and landscape value, recognized in the decree of four Protected Natural Areas that surround it (three at sea and one on land) by the National Commission of Protected Natural Areas. These natural qualities are attractive to both scientific institutions present year-round and to international real estate developers that have already bought an important amount of land.

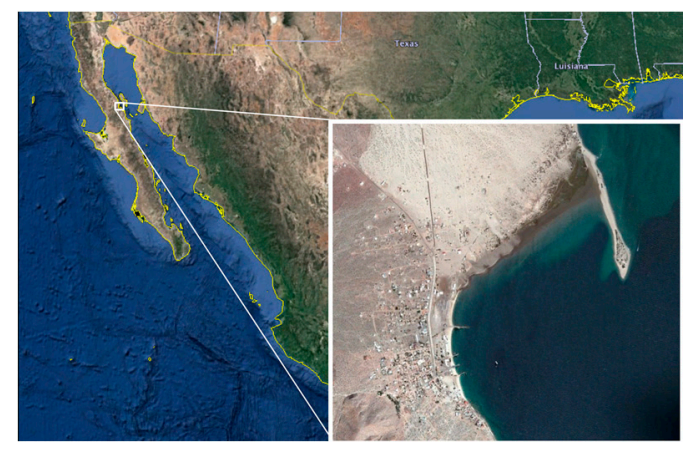

Figure 1. The Baja California Peninsula and location of Bahía de Los Ángeles, México. Image: Google, TerraMetrics, DigitalGlobe. 
The Strategic Planning Exercise of Bahía de Los Ángeles

Due to rising conflicts between land tenure, conservation, and tourism stakeholders, along with a flood episode in September of 2014 by Hurricane Odile, the municipality of Ensenada, through the Municipal Institute of Research and Planning, started working on the first Urban Development Program for Bahía de Los Ángeles. It began with a diagnostic workshop held in June 2016 (Figure 2) with communal land leaders, non-governmental associations and local, state and national government authorities. The information obtained was the base for this article.

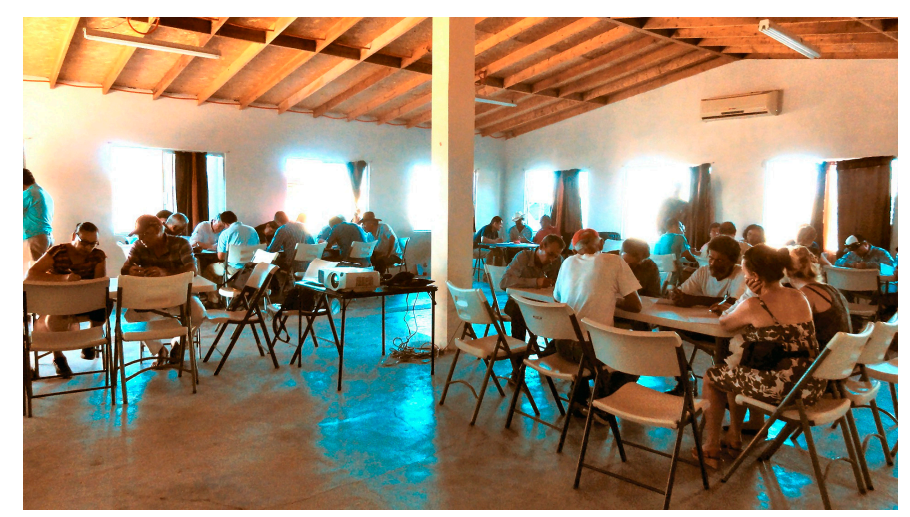

Figure 2. Strategic planning workshop at Bahía de Los Ángeles.

\section{Methodology}

\subsection{Network Topologies}

Networks are characterized by how their constituent parts, called nodes, are connected or related to other nodes by links [19] (Figure 3). The structure or topological features determine the structural properties and dynamics of networks. Similarly, there is also increasing evidence that behavior of complex urban systems is influenced by its topological organization [20]. Revealing the topology of urban issues helps discover functional relationships and key actors that can promote change in the network, making the policy-making process more effective by understanding its essential properties [6,21].

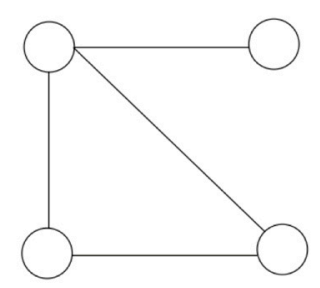

(a) Undirected graph

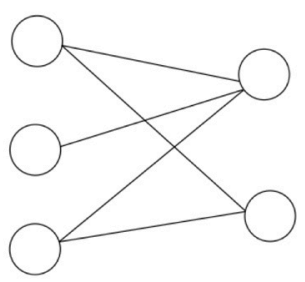

(c) Bipartite graph

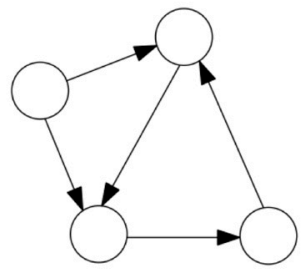

(b) Directed graph

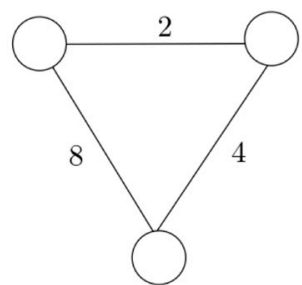

(d) Weighted graph

Figure 3. Examples of different types of networks according to topological features. Schematic from [18]. 


\subsection{Clustering}

A standard feature of a network topology is how it is organized in communities or clusters, defined as a set of densely connected nodes with sparser connections with other clusters [22] (Figure 4). Clustering, or exploratory data analysis [23], is related to dividing data objects into groups. It is often identified as an unsupervised classification because the number groups, or classes, are not known in advance due to lack of prior knowledge about the clusters, so only information present in the data set is used $[2,18,24]$. Cluster identification methods are related to network partitioning-one of which is Agglomerative Hierarchical Clustering-aimed at discovering divisions of networks into groups based on similarity or strength of a connection between nodes [25]. Agglomerative Hierarchical Clustering can have an agglomerative or divisive approach. In the process of translating this concept to the understanding of urban-related issues as nodes, clustering can be used as a structure indicator of a system that defines a human settlement.

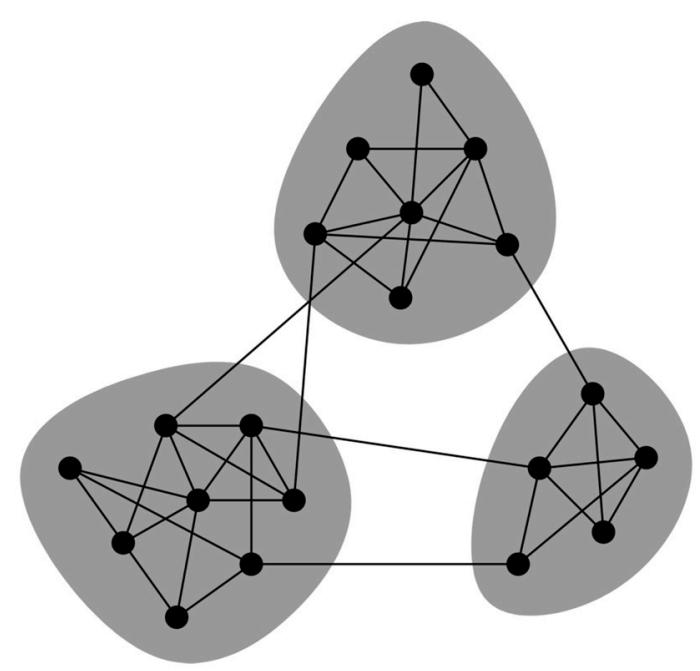

Figure 4. Densely connected nodes grouped in clusters with sparser connections with other clusters. Schematic from [22].

\subsection{Centrality}

Another feature related to networks is Centrality, a metric that identifies the most important nodes in a network, quantitatively evaluating its structural power in the sense of dominating other nodes [26]. There are several measures that capture the power of nodes in a network, including Degree Centrality, Closeness Centrality and Betweenness Centrality (Figure 5). Regarding this last metric, Hernandez and Mieghem state that Betweenness Centrality of a node $B_{k}$ is defined as the number of shortest paths between pairs of nodes that traverse a node or link $k$. Let $\sigma_{i j}$ be the number of shortest paths between nodes $i$ and $j$, and $k$ be either a node or a link. Let $\sigma_{i j}(k)$ be the number of shortest paths between $i$ and $j$ going through node $k$ [19]. The shortest paths betweenness for the node $k$ is

$$
B k=\frac{\sigma i j(k)}{\sigma i j}
$$




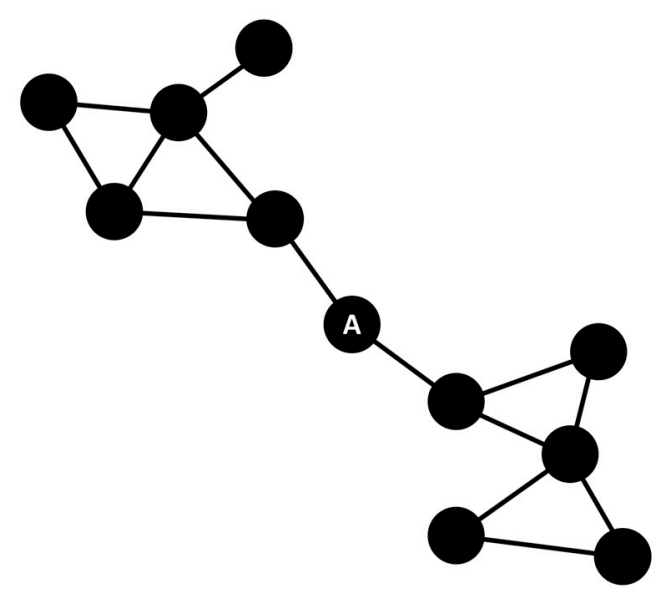

Figure 5. Node $A$ has a high Betweenness centrality value, as it is present in a substantial number of the shortest paths between all other nodes.

Network theory commonly associates this metric with the flow of information or resources through nodes of high Betweenness Centrality that act as bridges or access points between different parts of a network. However, in an urban planning context, we propose Betweenness Centrality as a measure of power similar to what Easley and Kleinberg define as "not so much a property of an individual as it is a property of a relation between two individuals" [14] (Figure 6) and as "power arising from the asymmetries in pairwise relations". Therefore, nodes with high Betweenness Centrality hold a pivotal position in the underlying structure, and we believe are of great importance for strategic planning, as they can be seen as the best opportunities to change the state of the system due to its connection and influence in all other nodes.

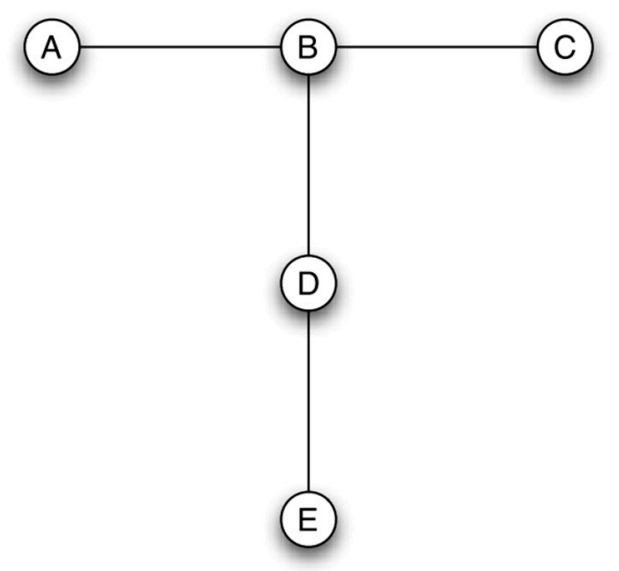

Figure 6. A social network of five people, with node $B$ occupying an intuitively powerful position. Schematic from [14].

\subsection{Methodology and Implementation}

As stated before, this methodology is meant to find a clustering structure and nodes with high Centrality in an otherwise heterogeneous list of urban-rural related issues provided by a diverse group of people. The first step was to assemble a SWOT (Strengths, Weaknesses, Opportunities and Threats) analysis workshop, which is a common methodology used in strategic planning as a way to get input from participants about current urban-rural issues, the urban state they aspire to achieve, and the positive and negative issues that can help or prevent its realization. This information was collected in Bahía de Los Ángeles through successive card filling rounds in which people answered the following questions: 
- What are the main problems that must be attended in Bahía de Los Ángeles (environmental, urban, economic, social, and institutional)?

- What is the desirable future for Bahía de Los Ángeles? (Vision)

- What internal conditions exist that favor the possibilities of achieving the Vision and contribute to reversing negative issues? (Strengths)

- What internal limitations exist for achieving the Vision? (Weaknesses)

- What external conditions exist that favor the possibilities of achieving the Vision and contribute to reversing negative issues? (Opportunities)

- What external limitations exist for achieving the Vision? (Threats)

This information was carefully summarized after the workshop into a list of 51 issues and became the foundation for a network structure analysis based on node clustering and Betweenness Centrality values. In this methodology, each issue is conceived as a node and influence among nodes conceived as links. To obtain this network, an identifier was assigned to each issue (I1, I2, I3, . . In) (Table 1) and arranged in a $51 \times 51$ cross-impact matrix that was given to each member of a multidisciplinary group composed of 8 experts in social and regional sciences, oceanography, architecture, engineering, and urbanism. Each expert individually identified links among issues and assigned a weight of influence value for each link ranging from 0 to $3(0=$ No influence; $1=$ Low influence; $2=$ Medium influence; and $3=$ High influence) in a row-influences-column fashion (for example, a value of 3 in the junction of row I6 with I22 means that issue 6 has a high influence in issue 22). Inputted values of all members were averaged to a final cross impact matrix that outputted 24 different fractional weight of influence values ranging from 0 to 3 (Table 2, refer to Supplementary Materials for a more readable size). A cluster detection algorithm was used along with a Betweenness Centrality value estimation. The above process is outlined in Figure 7.

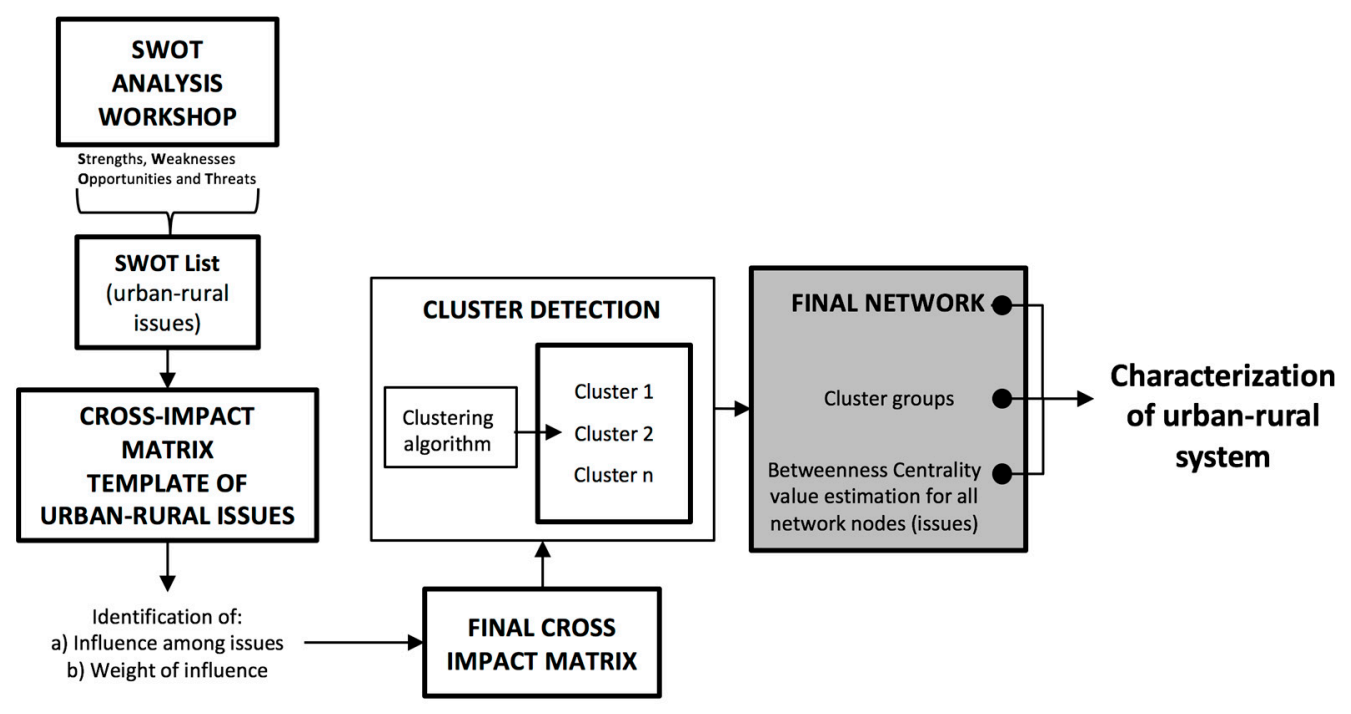

Figure 7. Methodological scheme. 
Table 1. The final list of urban-rural issues obtained from SWOT (Strengths, Weaknesses, Opportunities and Threats) analysis workshop.

\begin{tabular}{|c|c|}
\hline \multicolumn{2}{|c|}{ Weaknesses } \\
\hline I1 Sprawl & I16 Insecurity \\
\hline I2 Invasions and irregular settlements & I17 Restricted public access to the beaches \\
\hline I3 Land use incompatibility & I18 Scarce recreational activities \\
\hline I4 Land tenure conflicts and lack of legal certainty & I19 Inoperative aerodrome \\
\hline I5 Lack of infrastructure and services & I20 No foreign transport \\
\hline I6 Lack of long-term vision (planning) & I21 Lack of cell phone and Internet connectivity \\
\hline I7 Visual pollution & I22 Migration \\
\hline I8 Undefined peri-urban space & I23 Lack of tourism options \\
\hline I9 Limited access to housing & I24 Poor waste management and pollution \\
\hline I10 Shortage of medical services. & I25 Isolation of foreign groups \\
\hline I11 Absence of emergency and civil protection services & I26 Water shortage \\
\hline I12 Lack of political will and attention from authorities & I27 Unemployment. \\
\hline I13 Difficulty to carry out payment of public services & I28 Low human resources skills \\
\hline I14 Low relationship with government & I29 Low labor market flexibility and dynamism \\
\hline I15 Alcoholism and drug addiction & \\
\hline \multicolumn{2}{|c|}{ Threats } \\
\hline I30 Real estate threatened Protected Natural Areas & I34 Drug trafficking \\
\hline I31 Nautical Ladder mega project & I35 Human settlements in natural risk areas \\
\hline I32 Illegal fishing and hunting & I36 Concessions of federal maritime-terrestrial zones \\
\hline I33 Toxic mining & \\
\hline \multicolumn{2}{|c|}{ Strengths } \\
\hline I37 Rich natural attractions for tourism & I41 History, culture and heritage \\
\hline I38 Decreed Protected Natural Areas & I42 Organized community groups \\
\hline 139 Low impact sport and commercial fishing & I43 Outstanding locality role in the regional space \\
\hline I40 Existing ecological and urban planning programs & I44 High urban design potential \\
\hline \multicolumn{2}{|c|}{ Opportunities } \\
\hline I45 National and international low impact tourism market & I49 Scientific research by NGO and academic institutions \\
\hline I46 Increased environmental awareness from investors & I50 Foreign languages learning \\
\hline I47 Self-sustaining productive projects & I51 Water and waste recycling policy \\
\hline I48 Connection with Sonora state and south of the country & \\
\hline
\end{tabular}


Table 2. Final cross impact matrix.

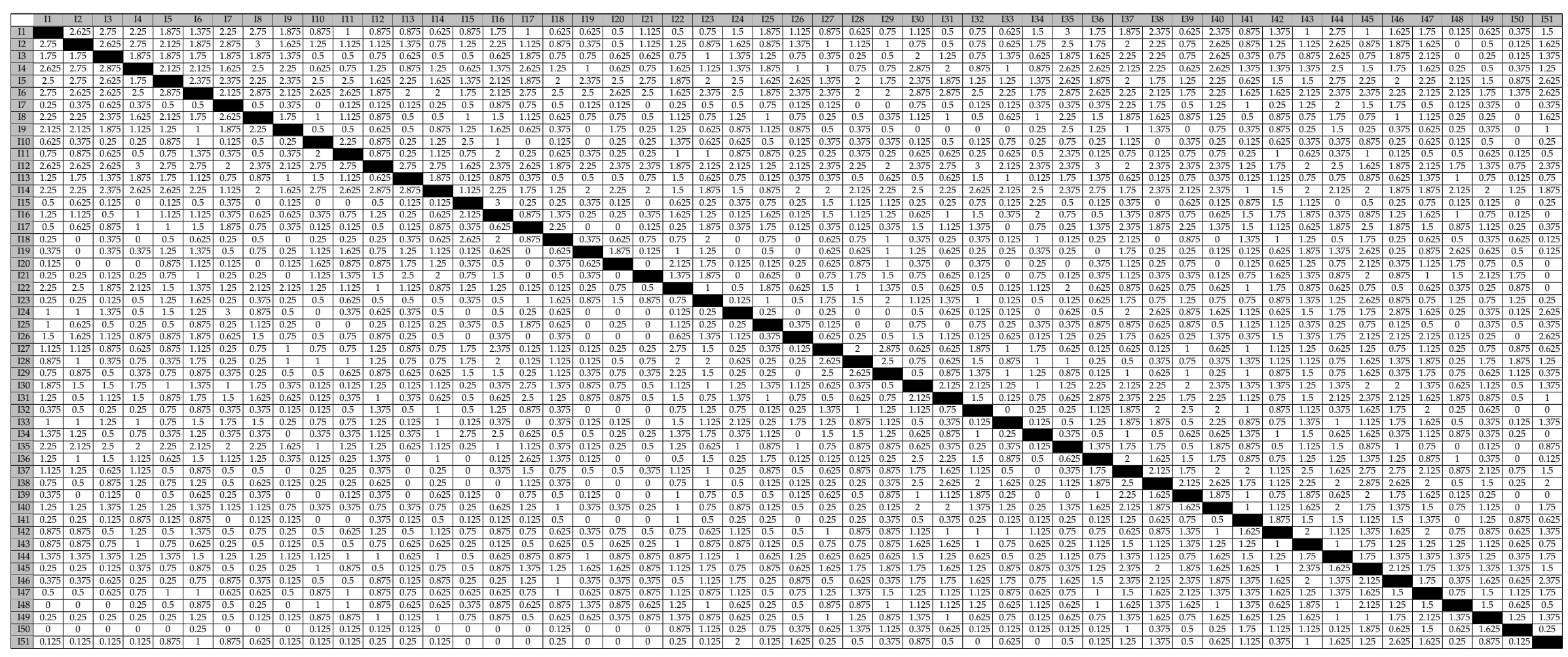




\subsection{Clustering of Urban-Rural Issues}

The Wakita-Tsurumi [27] clustering algorithm was used for cluster detection. It uses the metric of modularity $(Q)$ as a quality measure of division in a network, based on the idea that networks with inherent community structure deviate from random networks [18] and that networks with high modularity have denser connections inside a community, but fewer connections between nodes of different communities [27]. Modularity is defined as:

$$
Q=\sum_{i}\left(e_{i i}-a_{i}^{2}\right)
$$

where $e_{i i}$ represent the portion of edges that connect to vertices of the same type (within-community links) and $a_{i}^{2}$ represent the expected values of the same quantity in a network with the same community divisions but random connections between the nodes [25].

This algorithm was applied to the final cross impact matrix taking into account all 24 fractional weight of influence values.

\subsection{Betweenness Centrality of Urban-Rural Issues}

Besides clustering, the other metric used for structure characterization of an urban-rural issues network was an estimate of the Betweenness Centrality value for all nodes (issues).

\section{Results}

If all influence fractional values are taken into account from the final cross impact matrix, the resulting network (Figure 8) is a densely connected mesh with a high number of low influence links and a low number of high influence links (Figure 9). However, if all these values are inputted to the Wakita-Tsurumi algorithm, it outputs one single cluster due to an intrinsic resolution limit in the modularity metric used to cluster data [28].

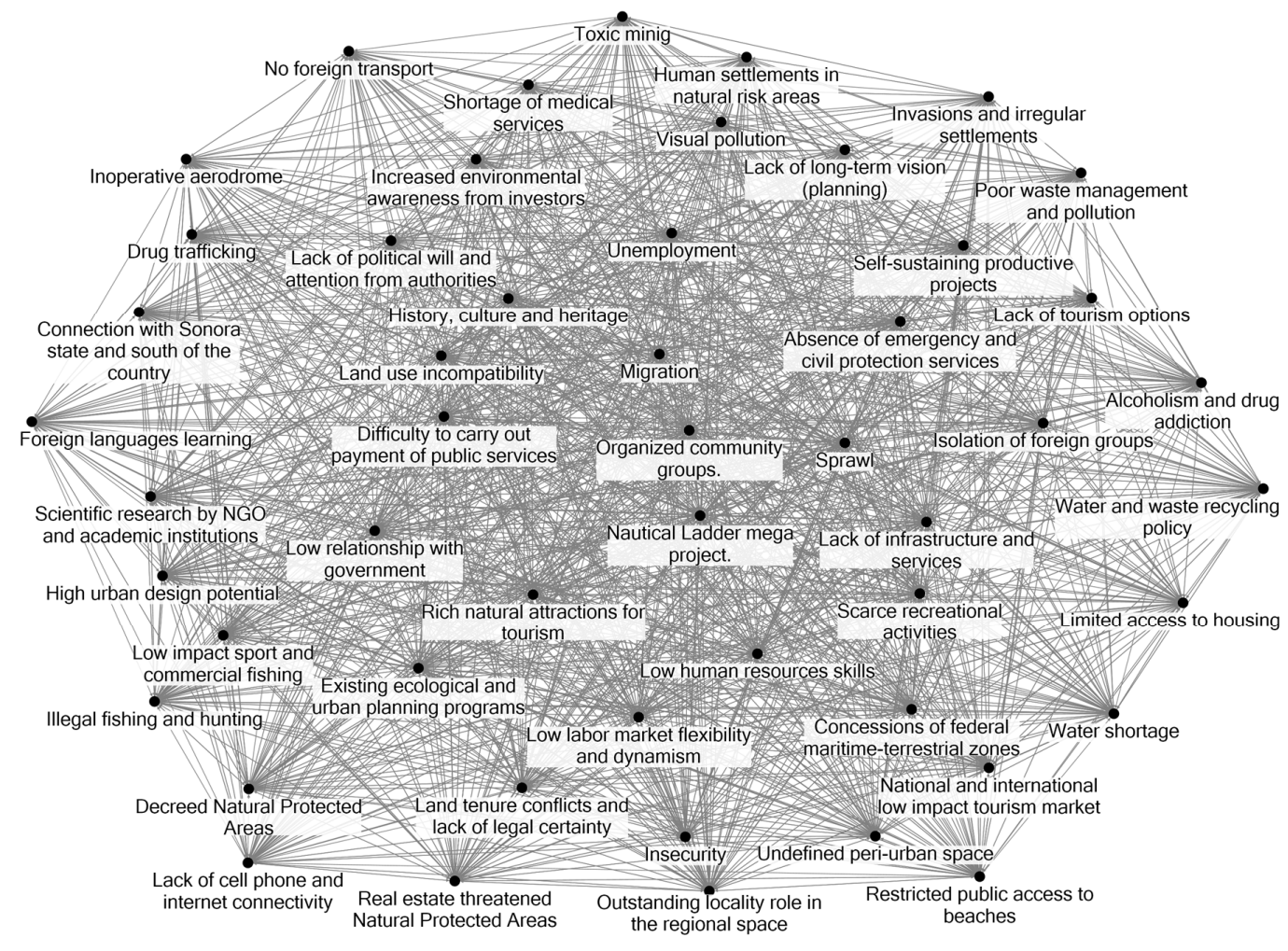

Figure 8. Initial network considering all weighted links. 


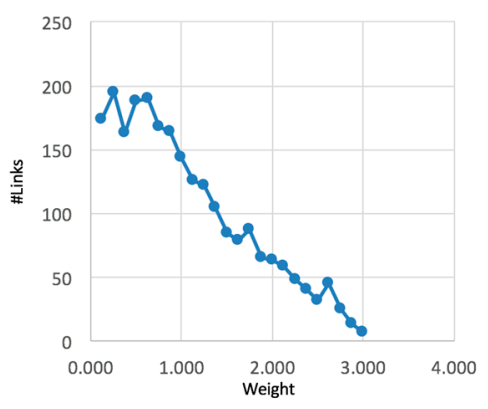

Figure 9. Distribution of links by weight of influence.

A way to obtain various clusters from the same matrix is to use a fraction of all its values. Different ranges of value were used until a number of clusters obtained were relevant and helpful to the strategic nature of an Urban Development Program in the sense of variety of clusters and coherence or "emerging theme" of nodes within clusters (not to be mistaken with similarity, as a cluster containing issues commonly classified as different can be related in a systems context). Finally, preferring the use of ranges that contained the highest values, the range value from 2.625 to 3.0 that outputted a network of seven clusters (Table 3 and Figure 10) was accepted.

Table 3. Clusters, metrics and themes of chosen network.

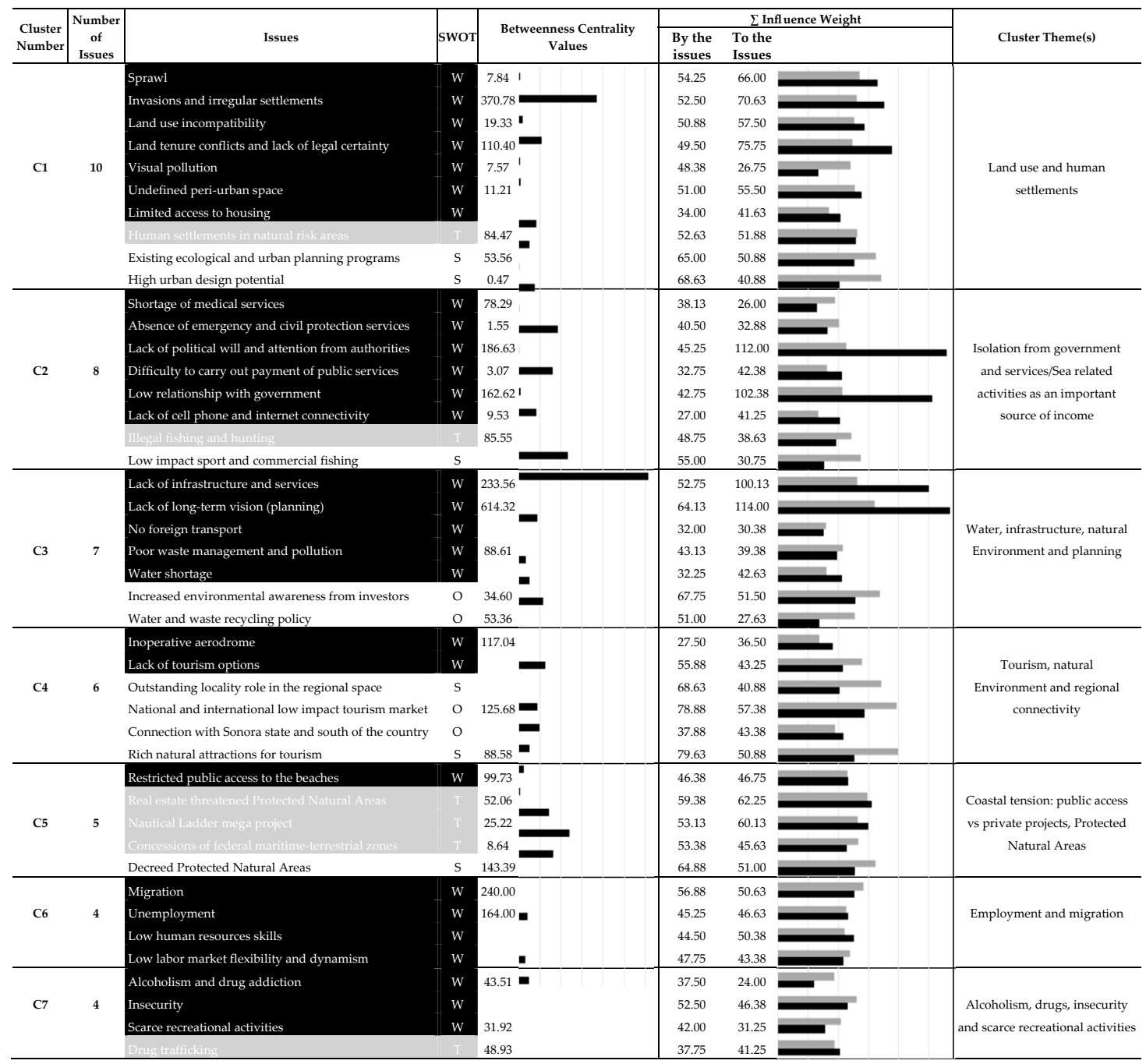




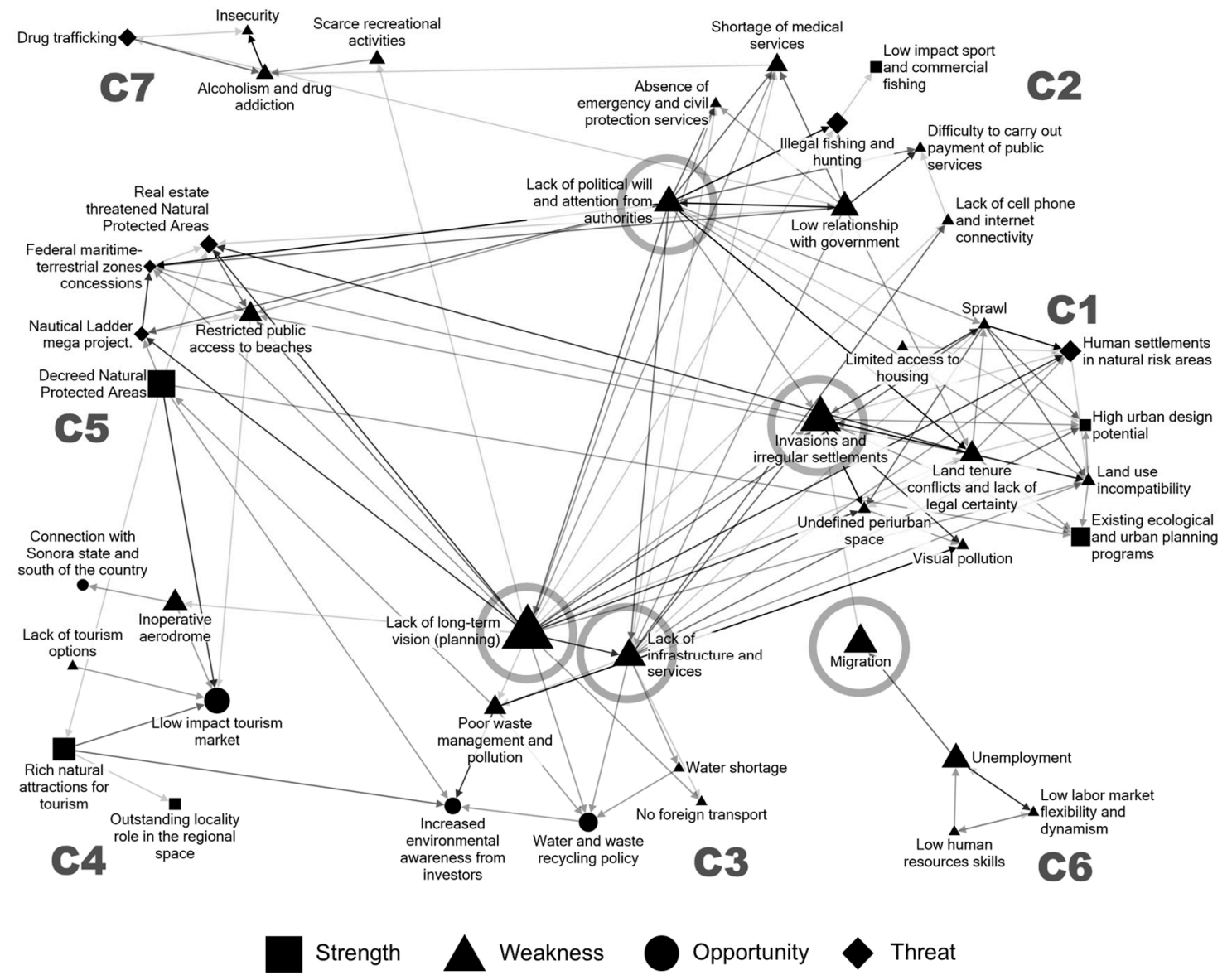

Figure 10. Chosen network arranged by clusters. Shape of node is SWOT analysis, size of node is Betweenness Centrality value: bigger size means higher values. Transparency of links is influence strength: darker color means higher influence. Direction of arrows means direction of influence. Nodes in circles represent high Betweenness Centrality values.

\section{Betweenness Centrality Values of Issues}

According to this seven-cluster network, issues with highest Betweenness Centrality value (issues that act as important access points between different parts of a network) were Lack of long term planning, Invasions and irregular settlements, Lack of infrastructure and services, Migration and Lack of political will.

\section{Discussion}

\subsection{Betweenness Centrality Analysis}

The Betweenness Centrality values of the network revealed that the current state of the locality could be affected if it is done by having an impact only in 5 of the 51 urban issues: Lack of long term vision, Invasions and irregular settlements, Lack of infrastructure and services, Migration and Lack of political will. This is useful for planners, as it can channel the limited governmental resources at hand only into issues that can have the greatest influence. Considering the connections these issues have with the rest of the network, it also aids to identify unsuspected influences between issues that may lead to unforeseen consequences, and thus help to design better planning policies. Lastly, there are similarities between how certain real-life events have recently triggered situations in Bahía de Los Ángeles and the structure of influences from the network of this exercise, suggesting that it can be used as part of a set of tools that can help anticipate the actions this system may take in real life. According to relations and influences of these issues with the rest of the network, they can be characterized as follows: 


\subsubsection{Lack of Long Term Vision}

Lack of long term vision, also known as lack of planning, has the most disproportioned number of influences: it influences 20 issues, but it is only influenced by one issue (Lack of political will and attention from authorities). This last statement had recent evidence when, in a Town Hall meeting in 2016, not all Councilors voted for elaborating the Urban Development Program of Bahía de Los Ángeles because of political reasons [29], which in turn provoked lobbying that delayed the planning process of the Program. Planning officials are currently working to change local and state law as a way to remove reasons that Councilors can use again to prevent the advancement of planning exercises. There is a similarity between this real-life action trying to change the lack of planning in the municipality, and the issue that must be acted upon to change the lack of planning according to the network obtained in this exercise: the lack of political will. This correspondence suggests that planning officials can use the network as a way to know the possible actions the community may take to solve its most pressing urban-rural issues.

Lack of long term vision mainly promotes the growth of human settlements in natural risk areas, permitting the advancement of mega projects in the coast threatening the integrity of decreed Natural Protected Areas, encouraging undefined peripheral growth and the lack of infrastructure.

\subsubsection{Invasions and Irregular Settlements}

The strongest influences that cause this state are Land tenure conflicts and lack of legal certainty and Lack of infrastructure and services. These causes differ from cities, where the main causes of conflict stem from issues of migration and lack of employment opportunities. To address problems in the context of Bahía de Los Ángeles, there must be a legal and urbanization focus, instead of the social and economic driven solutions more commonly associated with this issue. A legal focus is needed due to critical property issues like overlaps and land that is owned at the same time by different and conflicting people. An urbanization focus is needed due to the lack of Internet services and proper coverage of water and sewage systems. The Invasions and irregular settlements issue has in turn consequences, mainly on Visual pollution and Undefined peri-urban space, and indirectly on Land tenure conflicts and lack of legal certainty and on Sprawl. Unlike cities where invasions are more likely to be on the periphery, in Bahía de Los Ángeles take center stage regarding Restricted public access to the beaches trough the role of Land tenure conflicts and lack of legal certainty. Invasions and irregular settlements do not have a significant relation to transport or infrastructure, as these two elements are virtually non-existing in this setting, and which is a significant departure where transport is a key factor to understand urban sprawl [30,31].

\subsubsection{Lack of Infrastructure and Services}

Its relation to other issues suggests that the current Lack of infrastructure and services contributes positively to the Increased environmental awareness from investors and Water and waste recycling policy. Thus, what can be appreciated as an undesired state of the locality, it nevertheless has an indirect positive influence on environmental issues, and measures must be designed to preserve this state once Bahía de Los Ángeles achieves major infrastructure coverage as one of the strongest motives for conservation will no longer exist. Although the locality has a small electrical plant and running water service, the main cause of not having proper infrastructure is the Lack of long term vision (planning)—water needs, sewage, electricity and other services have never been quantified, and an integrated plan for line distribution has not been designed. This may explain the slow growth of the locality showed in census data, Lack of cell phone and internet connectivity, and no exploitation of High urban design potential. 


\subsubsection{Migration}

The Migration issue stem from a combination of Unemployment, Low human resource skills and Low labor market flexibility and dynamism. This combination of structural issues may be the causes that make the locality expel population as stated by locals in the workshop and manifest in a slow growth of Bahía de Los Ángeles.

\subsubsection{Lack of Political Will and Attention From Authorities}

As stated above, it has an important influence over the Lack of long term vision (planning), but also over a large number of other issues, mainly those related to Land tenure conflicts and lack of legal certainty, Illegal fishing and hunting and occupation of coastal zones that must first be authorized by the government. Worth noticing is how this issue influences planning exercises trough current Land tenure conflicts and lack of legal certainty, which is a landmark characteristic of Bahía de Los Ángeles that not even other rural communities of the municipality of Ensenada have in the same degree, and that was stated by participants on a follow-up workshop done in Bahía de Los Ángeles in early 2017 as this paper was being written.

\subsection{Clustering Analysis}

A relevant feature of this methodology is the emergence of a coherent and thematic structure that clusters the input of stakeholders, officials, and professionals that is unique to Bahía de Los Ángeles and evidently different from the generic structure used by public agencies when making urban development programs (Table 4). This thematic structure is valuable to planners as it serves as the framework for a focused diagnostic of the territory that reveals the main issues and their relations that act upon it, preventing the planner of doing time-consuming exhaustive analysis of all elements involved in an urban system that most surely do not have the same relevance, and that ignores a scheme that can help understand the possible consequences of acting on specific urban issues.

Table 4. Diagnostic structure comparison.

\begin{tabular}{|c|c|}
\hline Traditional Generic Structure & Structure Given by Clustering \\
\hline 1. Natural Physical Environment & 1. Land use and human settlements \\
\hline 2. Transformed Physical environment & $\begin{array}{l}\text { 2. Isolation from government and services/Sea related activities } \\
\text { as an important source of income }\end{array}$ \\
\hline 3. Socioeconomic aspects & 3. Water, infrastructure, natural environment and planning \\
\hline \multirow[t]{4}{*}{$\begin{array}{l}\text { 4. Urban Development Administration } \\
\text { and Management }\end{array}$} & 4. Tourism, natural environment and regional connectivity \\
\hline & $\begin{array}{l}\text { 5. Coastal tension: public access vs. private projects, Protected } \\
\text { Natural Areas }\end{array}$ \\
\hline & 6. Employment and migration \\
\hline & 7. Alcoholism, drugs, insecurity and scarce recreational activities \\
\hline
\end{tabular}

Cluster 1: Land use and human settlements

According to the influence it receives from other issues, the current state of land use and human settlements is affected by Migration, Lack of long term vision (planning), Lack of political will and attention from authorities, Lack of infrastructure and services and Real estate threatened Protected Natural Areas. Various issues of Cluster 1 are dynamic in the sense that they are both influential and are very influenced by other system's issues. These issues are Sprawl, Invasions and irregular settlements, Land use incompatibility and Land tenure conflicts and lack of legal certainty, and according to the SWOT analysis, they are all Weaknesses or inner obstacles for achieving the desired urban vision of Bahía de Los Ángeles. The Invasions and irregular settlements issue has by far the highest Betweenness Centrality value of this 
cluster and is second in all the network issues after the issue of Lack of long term vision (planning), so it must be one of the main issues that the Urban Development Program focuses on resolving.

Cluster 2: Isolation from government and services/Sea related activities as an important source of income

The eight issues of Cluster 2 encompass the theme related to the isolated nature of the locality. It is also related to the sea as an important source of income. Low relationship with government and Lack of political will and attention from authorities are two of the most influential issues of all the network (both being Weaknesses,) and the last one having one of the highest Betweenness value in all the network, given that so many other issues are importantly related to it. Illegal fishing and hunting activities and Low impact sport and commercial fishing are passive issues, as they do not have a relevant influence compared to other issues and are strongly influenced and vulnerable. Commercial fishing is considered one of the few strengths of Bahía, so protective measures to these activities must be established in the Urban Development Program, along with a greater government and communications presence through new offices and infrastructure.

Cluster 3: Water, infrastructure, natural environment and planning

Cluster 3 is relevant as it has more variety of issues than the previous clusters and insights into a system by itself, and it also holds two issues that have both highest values in system influence and Betweenness centrality: Lack of infrastructure and services and Lack of long-term vision (planning), this last one with the highest Betweenness Centrality value of all the network of issues. Although this cluster is relevant, most of its issues are Weaknesses. It also holds two of the few Opportunities of Bahía, Increased environmental awareness from investors and Water and waste recycling policy, both of which have a low influence over the rest of the issues of the entire network. It was also surprising that Water shortage was considered a passive issue in the sense that it had neither a relevant influence nor it was notably influenced. Because the Lack of long-term vision (planning) issue acts as the primary gateway in the network between other issues, it is expected that the conclusion of the Urban Development Program will have a relevant impact on the urban-rural system, although there is a risk of failure in its implementation if the issue of Lack of political will and attention from authorities still prevails when the program its implemented.

Cluster 4: Tourism, natural environment, and regional connectivity

The six issues of Cluster 4 are understandably related in this locality due to its outstanding environmental value: tourism and its needed connectivity. This cluster had the most influenced issues of the entire system, National and international low impact tourism market and Rich natural attractions for tourism, which were considered as a Strength and Opportunity, respectively, but surprisingly do not have the expected influence in the network. The cluster also holds the highest number of positive issues per cluster, as Outstanding locality role in the regional space and Connection with Sonora state and south of the country were also Strengths and Opportunities. Notwithstanding the importance that these issues may have, a characteristic of this cluster is that all of its issues do not have a significant influence in the network compared to other issues, nor the Betweenness values. The composition of this cluster demands a particular attention to the regional connectivity context in the Urban Development Program, a scale not normally studied in this type of planning instruments but much needed for Bahía as stated by the issues of this cluster.

\section{Cluster 5: Coastal tension: public access vs. private projects, Protected Natural Areas}

The five issues of Cluster 5 have a similar theme, similar to Cluster 4, but are focused towards the tensions that prevail in the coast between public access to beaches and real estate projects that may be built directly in front of them, all in the context of the various decreed Protected Natural Areas that surround Bahía de Los Ángeles. This cluster is relevant in the sense that has two issues that 
highly influence the system, and which are also highly influenced: the official Nautical Ladder mega project and Real estate threatened Protected Natural Areas, both considered as Threats by the majority of workshop participants. These natural areas were valued as a Strength of Bahía de Los Ángeles but highly influenced by the network and low influence to the network. The nature of this cluster demands great coordination between federal, state and municipal governments that must be reflected in the policies of the Urban Development Program. Because Protected Natural Areas are of Federal jurisdiction, real estate projects are promoted by the state government and the Program is designed by the municipal government.

Cluster 6: Employment and migration

Cluster 6 holds one of the issues with the highest Betweenness value in the system, Migration, and its relation to Employment, Low human resources skills and Low labor market flexibility and dynamism. All four issues are Weaknesses and have a low influence on the network and are highly influenced. Because migration acts as an important gateway between other issues of the system, the Urban Development Program must have an important social focus, not commonly associated with a Program more related to physical urban aspects of human settlements.

Cluster 7: Alcoholism, drugs, insecurity and scarce recreational activities

The four issues of Cluster 7 are similar to Cluster 6 in the sense that they have a distinctly social theme, but in this case related to the challenges of Drug trafficking, Alcoholism and drug addiction, and Scarce recreational activities. They are obviously Threats and Weaknesses, but have a low influence in relation to other issues and consistently having very low Betweenness Centrality values, so it is inferred that these issues do not pose relevant problems to Bahía de Los Ángeles.

A few issues were understandably left out of any cluster, such as Foreign language learning, which had the lowest influence/influenced values of all the system, or Isolation of foreign groups. An issue that was expected to be clustered due to its strong relation to the rich natural environment of Bahía de Los Ángeles was Scientific research by NGO and academic institutions, but it did not have relevant influence on a sufficient number of issues to be clustered. The remaining issues left out were Toxic Mining; History, culture and heritage; Organized community groups and Self-sustaining productive projects.

The network of seven clusters reveals that three of them are significantly less connected to the rest, and they encompass issues of social and environmental nature. They are also mainly passive, meaning that their sparse connections are influences from the network. Due to this high sensitivity to influence, one of the primary objectives of an urban plan for the locality of Bahía de Los Ángeles must be the protection of its natural attractions and the reinforcing of a low impact tourism, to be achieved mainly through the improvement of the aerodrome and the promotion of the federal decrees of its Natural Protected Areas, which has not been done until now.

\section{Conclusions}

In this paper, we adapted concepts of Clustering and Betweenness Centrality from network theory to find clusters in a non-spatial network of urban-rural issues, and to identify which of these issues act as important communication bridges. Results revealed unsuspected indirect influences among issues, parallelisms to recent real-life events, as well as marked differences in the way issues behave in a rural context in contrast to an urban context. These differences include the fact that irregular settlements have a smaller impact on infrastructure, and that they play a major role on public accessibility to beaches due to land tenure conflicts instead of employment opportunities and lack thereof. Our results also suggested actions that the Urban Planning Program of Bahía de Los Ángeles should take to tackle important issues, such as treating irregular settlements from a legal and infrastructure perspective, reinforcing low impact tourism trough the promotion of federal Natural Protected Areas, improvement of the existing aerodrome, the need to solve irregular settlements as a way to change the state of the rest of the urban system, the protection of commercial fishing, and the importance to acquire a 
regional scale regarding connectivity. It also hinted the need of a social focus of the urban development program. Lastly, results showed how land tenure conflicts defer advancement in planning efforts and that the lack of infrastructure helps gain environmental awareness.

Notwithstanding its usefulness, the methodology also poses challenges regarding the classification of resulting clusters. Traditional urban planning exercises do not identify complex relations among urban related issues, and instead group elements that have similar characteristics. It is not the case from the perspective of networks: emerging clusters contain apparently different issues, as some relations may not be obvious to an urban planner, and may group in an unexpected manner. Translating this methodology into a traditional urban development program diagnostic has also turned out to be a challenge, as issues tend to overlap-or there is a similarity between cluster themes, contrary to traditionally presentation of urban related issues in a separate way. We see this as an opportunity to revise how we look at urban systems and translate it into new ways of approaching the design of urban development programs, and also as a demand for more efficient multidisciplinary work between professionals as a way to create better urban development policies.

Author Contributions: All the authors conceived and designed the study; Manuel Castañón-Puga and Carelia Gaxiola-Pacheco provided methodological advice. Javier Sandoval-Felix the field survey and analyzed the data. Javier Sandoval Felix and Eugenio Dante Suarez wrote the paper. All authors read and approved the manuscript.

Conflicts of Interest: The authors declare no conflict of interest.

\section{References}

1. SEDESOL. Plan o Programa Municipal de Desarrollo Urbano: Guia Metodologica; Direccion General de Desarrollo Urbano y Suelo: Distrito Federal, México, 2007.

2. Murgante, B.; Borruso, G.; Lapucci, A. Geocomputation and Urban Planning; Springer: Berlin/Heidelberg, Germany, 2009; Volume 176.

3. Portugali, J. Complexity, Cognition and the City; Springer: Heidelberg, Germany, 2011.

4. Portugali, J.; Meyer, H.; Stolk, E.; Tan, E. Complexity Theories of Cities Have Come of Age; Springer Science \& Business Media: Berlin, Germany, 2012.

5. Walloth, C.; Gurr, J.M.; Editors, J.A.S. Understanding Complex Urban Systems: Multidisciplinary Approaches to Modeling; Springer: New York, NY, USA; London, UK, 2014.

6. Alves, B.; Sakowski, P.; Tovolli, M. Modeling Complex Systems For Public Policies; Alves, B., Sakowski, P., Tovolli, M., Eds.; Institute for Applied Economic Research: Brasília, Brazil, 2015; Volume 37.

7. OECD Global Science Forum. Applications of Complexity Science for Public Policy: New Tools for Finding Unanticipated Consequences and Unrealized Opportunities; OECD: Paris, France, 2009.

8. Sayama, H. Introduction to the Modeling and Analysis of Complex Systems; Milne Library: Geneseo, NY, USA, 2015.

9. Kenbeek, S.D.; Bone, C.; Moseley, C. A Network Modeling Approach to Policy Implementation in Natural Resource Management Agencies. Comput. Environ. Urban Syst. 2016, 57, 155-177. [CrossRef]

10. Alberti, M. Advances in Urban Ecology; Springer: New York, NY, USA, 2008.

11. De Roo, G.; Silva, E.A. A Planner's Encounter with Complexity; Ashgate Publishing, Ltd.: Farnham, UK, 2010.

12. Xie, F.; Levinson, D.M. Evolving Transportation Networks; Springer: New York, NY, USA, 2011.

13. Batty, M. Cities as Complex Systems: Scaling, Interactions, Networks, Dynamics and Urban Morphologies; CASA Working Paper Series; Springer: Berlin, Germany, 2008.

14. Easley, D.; Kleinberg, J. Networks, Crowds, and Markets: Reasoning about a Highly Connected World. Science 2010, 81, 744 .

15. Heppenstall, A.; Crooks, A.; See, L.; Batty, M. Agent-Based Models of Geographical Systems; Springer: London, UK; New York, NY, USA, 2013; Volume 27.

16. Basse, R.M.; Omrani, H.; Charif, O.; Gerber, P.; Bódis, K. Land Use Changes Modelling Using Advanced Methods: Cellular Automata and Artificial Neural Networks. The Spatial and Explicit Representation of Land Cover Dynamics at the Cross-Border Region Scale. Appl. Geogr. 2014, 53, 160-171. [CrossRef] 
17. Weiler, R.; Engelbrecht, J.; Cadmus, J. The New Sciences of Networks \& Complexity: A Short Introduction. Cadmus 2013, 2, 131-141.

18. Malliaros, F.D.; Vazirgiannis, M. Clustering and Community Detection in Directed Networks: A Survey. Phys. Rep. 2013, 533, 95-142. [CrossRef]

19. Hernandez, J.M.; Van Mieghem, P. Classification of Graph Metrics; Delft University of Technology: Mekelweg, The Netherlands, 2011; pp. 1-20.

20. Albert, R. General Network Theory. In LACUS: Forum XXXII Networks; The Linguistic Association of Canada and the United States (LACUS): Hamilton, ON, Canada, 2006.

21. Ball, P. Why Society Is a Complex Matter; Springer: Berlin/Heidelberg, Germany, 2012.

22. Newman, M.E.J. Modularity and Community Structure In Networks. Proc. Natl. Acad. Sci. USA 2006, 103, 8577-8582. [CrossRef] [PubMed]

23. Xu, R.; Wunsch, D. Survey of Clustering Algorithms. IEEE Trans. Neural Netw. 2005, 16, 645-678. [CrossRef] [PubMed]

24. Tan, P.-N.; Steinbach, M.; Kumar, V. Introduction to Data Mining; Addison-Wesley Longman Publishing Co., Inc.: Boston, MA, USA, 2005; Chapter 8.

25. Newman, M.E.J.; Girvan, M. Finding and evaluating community structure in networks. arXiv 2003, arXiv:cond-mat/0308217. [CrossRef] [PubMed]

26. Coscia, M.; Giannotti, F.; Pedreschi, D. A classification for community discovery methods in complex networks. arXiv 2012, arXiv:1206.3552. [CrossRef]

27. Wakita, K.; Tsurumi, T. Finding community structure in mega-scale social networks. arXiv 2007, arXiv:cs/0702048.

28. Fortunato, S.; Barthelemy, M. Resolution limit in community detection. Proc. Natl. Acad. Sci. USA 2007, 104, 36-41. [CrossRef] [PubMed]

29. Madrigal, N. Aprueba el Cabildo Polémico Dictamen. Available online: http:/ /www.elvigia.net/general/ 2016/6/3/aprueba-cabildo-polemico-dictamen-238355.html (accessed on 3 June 2017).

30. Inostroza, L.; Baur, R.; Elmar, C. Urban Sprawl and Fragmentation in Latin America: A Comparison with European Cities. The Myth of the Diffuse Latin American City; Lincoln Institute of Land Policy: Cambridge, MA, USA, 2010.

31. Inostroza, L.; Baur, R.; Csaplovics, E. Urban Sprawl and Fragmentation in Latin AMerica: A Dynamic Quantificationand Characterization of Spatial Patterns. J. Environ. Manag. 2013, 115, 87-97. [CrossRef] [PubMed] 